\title{
A Cone-Beam Computed Tomography Scanning of the Root Canal System of Permanent Teeth among the Moscow Population
}

\author{
Svetlana Razumova, Anzhela Brago, Lamara Khaskhanova, Ammar Howijieh, \\ Haydar Barakat $\mathbb{D}$, and Ashot Manvelyan \\ Peoples' Friendship University of Russia (RUDN University), 6 Miklukho-Maklaya Street, Moscow 117198, Russia \\ Correspondence should be addressed to Haydar Barakat; dr.haydarbarakat@yahoo.com
}

Received 1 March 2018; Accepted 29 May 2018; Published 25 September 2018

Academic Editor: Gianrico Spagnuolo

Copyright (C) 2018 Svetlana Razumova et al. This is an open access article distributed under the Creative Commons Attribution License, which permits unrestricted use, distribution, and reproduction in any medium, provided the original work is properly cited.

Background. Successful endodontic treatment requires a significant knowledge of root canal anatomy. The aim of this study was to evaluate the root and root canal number of permanent teeth among the Moscow population using cone-beam computed tomography (CBCT) scanning. Materials and methods. 300 CBCT images of subjects were analyzed to study the anatomy of roots and root canal system of each tooth. The collected data were analyzed using IBM SPSS statistics software 22.0 version. Results. The maxillary incisors and canines had one root with one canal in 100\%. Maxillary premolars had one root with one or two canals and two roots with two canals, while mandibular premolars were single-rooted with one or two canals. Maxillary first and second molar had three separated roots, and the prevalence of four canals was more often in first molars. Mandibular molars had two roots with different number of canals. Conclusion. The root canal system varies greatly among populations and even in different individuals within the same population; thus, using CBCT scanning is an effective technique in investigating the root canal system.

\section{Background}

The success of endodontic treatment depends on the precise knowledge of root and root canal anatomy, which is an important challenge due to the complexity of the root canal system and the anatomical variations $[1,2]$. This knowledge helps the clinicians in endodontic treatment planning and decreases the percent of endodontic treatment failure. Many studies have been conducted to determine the anatomy and morphology of root canal system using different techniques [3-9]. Recently, with the development of cone-beam computed tomography (CBCT) technique, it became possible to study the anatomy of teeth, due to the high-quality threedimensional (3D) images obtained from CBCT. This image allows studying the anatomy of the jaws, the morphology of teeth, and their root canal system [3]. Many studies have used this technique to find out the anatomy of root canal system especially in the molar regions $[3,6,8]$.
Root canal morphology has been classified using different ways by several investigators in the literature [10-12]. Weine et al. [12] classified it into four types depending on the pattern of division of the main root canal of a tooth along its course from the floor of the pulp chamber to the root apex. Vertucci [10] also classified the root canal morphology in a more descriptive manner into eight types. This classification has been widely used by many researchers to classify the canal system of different teeth.

It is known that the number of teeth roots and the anatomy of root canal system vary among the world population, and to date, there are still no studies about the anatomy of roots and root canals in Russian Federation, where dental practitioners still use the data obtained from foreign authors on the anatomy of root canals in planning the endodontic treatment. The aim of this study was to investigate the anatomy of root and root canal system among the Moscow population using CBCT technique. 


\section{Materials and Methods}

300 subjects aged $20-70$ years were enrolled in this study, from those attending the diagnostic center (LLC Zolotoye Secheniye) for 3D radiological scanning in the period between January 2017 and November 2017. The study protocol was approved by the Ethics Committee in People's Friendship University of Russia (RUDN University), Moscow, Russia. A written consent was signed by all subjects, including who participated in this study. CBCT images were taken using a 3D eXam ${ }^{\circledR}$ dental tomography scanner (KaVo, Biberach, Germany) with standard exposure settings ( $23 * 17 \mathrm{~cm}$ field of view; $0.3 \mathrm{~mm}$ voxel size; $110 \mathrm{kv} ; 1.6-20 \mathrm{~s})$ and were viewed by three examiners in a semidark room using I-CAT viewer software (version 10, Hatfield, England). All teeth were evaluated in axial, coronal, and sagittal planes, and the number of roots and the number of canals in each tooth were recorded. The presence of additional canals especially in the molar regions was recorded.

2.1. Statistical Analysis. Data were processed using the software (SPSS v 22 for win, IBM, Chicago, IL), and descriptive data were processed to analyze the percentage of roots and root canals in each tooth.

\section{Results}

300 CBCT scans of 300 subjects with mean age of $49.91 \pm$ 14.01 were analyzed. All the maxillary incisors had one root with $100 \%$ and one canal with $100 \%$. First and second maxillary molars had three roots with $100 \%$, and third molar recorded one root in $33.7 \%$ and three roots in $47.9 \%$. Data for maxillary teeth including the number of roots and root canals are shown in (Table 1).

For mandibular teeth, data were the following: central and lateral incisors and canines showed one root and one canal in $99.4 \%, 99.2 \%$, and $99.8 \%$, respectively. First molars had two roots in $100 \%$, and second molars had one root in $0.5 \%$ and two roots in $99.5 \%$. Data for mandibular teeth are shown in (Table 2).

\section{Discussion}

The knowledge of the anatomy of the root canal system is the gold standard in successful endodontic treatment, and studying root and canal morphology has endodontic and anthropological significance. This study evaluated the roots and root canal system among the Moscow population using CBCT scanning. The advantages of CBCT scanning are its high accuracy, minimal distortion, and 3D visualization. Moreover, it is a nondestructive technique and can provide specific data [3].

When analyzing the anatomy of the maxillary anterior teeth, 510 central incisors, 500 lateral incisors, and 540 canines were recorded, and one root with one canal was identified in $100 \%$ of cases. These data are comparable with the results obtained from other studies on the anatomy of central incisors in USA [10], Mexico [11], Turkey [13], and Chennai urban [14]. The presence of two canals in lateral incisors was found in $13.7 \%$ of cases in a study by Calișkan et al. (Turkey) [13], in 9.5\% of cases by Sert and BayirliIn (Turkey) [15], and in $2 \%$ in a study by Jain et al. (Chennai urban) [14]. The prevalence of two canals in canines was $3.9 \%, 2-4 \%, 4 \%$, and $18.4 \%$ in studies by Calişkan et al. [13], Sert and Bayirli [15], Jain et al. [14], and Amardeep et al. [16] respectively. This difference in results could be attributed to the evaluation method, sample size, and racial differences.

According to the current study, the anatomy of root canals of maxillary first premolar was variable, two roots were identified in $91.3 \%$ of cases and $8.7 \%$ of cases were one rooted, and the first premolar recorded one root and two canals in $2.6 \%$ and one canal in $6.1 \%$ of cases. Similar data obtained in the studies of Bulut et al. (Turkey) [17], Pecora et. al. (Brazil) [18], Kerekes and Tronstad (Norway) [19], Green [20] (USA), Ok et al. (Turkey) [21], and Burklein et.al. (Germany) [22]. Pineda and Kuttler (Mexico) [11] have revealed in their studies a single-canal first premolar in $50.1 \%$ and two canals in $49.4 \%$ of cases.

The maxillary second premolar with one root was determined in $26.5 \%$ of observations and with two separated roots in $73.5 \%$ of cases according to the data of the current study, and two canals were recorded in $73.5 \%$ of cases. This coincides with the results of Awawdeh et al. (Jordan) [23], where one canal was found in $13.8 \%$ and $84.1 \%$ had two canals; the results of Elnour et al. (Saudi Arabia) [24], where two canals were recorded in $65 \%$ of cases; and the results of Bürklein et al. (Germany) [22], where $56.3 \%$ of cases had two canals. Bulut et al. (Turkey) [17] recorded one canal in $82.1 \%$ of the cases and two canals in $17.8 \%$.

The maxillary first molar was analyzed by all researchers in detail by the number of canals in each root. Three separated roots were identified in $100 \%$ of cases. The number of canals varied from 3 to 5 . The four-canal root system occurred in $59.8 \%$ of cases, and the localization of the two canals takes place more often in the mesiobuccal root (MB) and also occurred in the distobuccal root (DB). These results are comparable with the results of Pomeranz and Fishelberg (USA) [25], where $48 \%$ of cases had two canals in MB. Wasti et al. (Pakistan) [26] recorded a percent of two canals in MB in 43.4\%, and Pineda and Kuttler (Mexico) [11] defined two canals in $48.5 \%$ of cases. This significantly varies from the results of Imura et al. (Japan) [27], where $88.2 \%$ of cases had two canals in the MB, and of Kim et al. (Korea) [8], where two canals in MB were found in $63.59 \%$ and $1.25 \%$ in DB. Ghoncheh et al. (Iran) [28], Martins et al. (Caucasian population) [29], Ratanajirasut et al. (Thai) [30], Silva et al. (Brazil) [31], and Guo et al. (North America) [32] recorded four-canal system in $46 \%, 71 \%, 63.6 \%, 42.63 \%$, and $68.2 \%$ of cases, respectively. Ceperuelo et al. (Spain) [33] defined fourcanal system in $92.3 \%$ of cases.

The maxillary second molar consisted of three separated roots in $100 \%$ of cases, and the prevalence of four canal systems was identified in $51.5 \%$ of cases (two canals in MB). This agreed with the published studies of Shalabi et al. (Ireland) 50\% [34], Kulild and Peters (USA) 45.8\% [35], Alavi et al. (Thailand) $44.6 \%$ [36], Kim et al. (Korea) 34.39\% [8], Martins et al. (Caucasian population) $44 \%$ [29], and Ratanajirasut et al. (Thai) 29.4\% [30] of the prevalence of two 
TABLE 1: Anatomy of roots and root canals in maxillary teeth.

\begin{tabular}{|c|c|c|c|c|c|}
\hline Tooth & Number of studied teeth & Roots & $N(\%)$ & Canals & $N(\%)$ \\
\hline Central incisor & 510 & 1 & $510(100 \%)$ & 1 & $510(100 \%)$ \\
\hline Lateral incisor & 500 & 1 & $500(100 \%)$ & 1 & $500(100 \%)$ \\
\hline Canine & 540 & 1 & $540(100 \%)$ & 1 & $540(100 \%)$ \\
\hline \multirow[t]{2}{*}{ First premolar } & \multirow[t]{2}{*}{460} & 1 & $40(8.7 \%)$ & $\begin{array}{l}1 \\
2\end{array}$ & $\begin{array}{l}28(6.1 \%) \\
12(2.6 \%)\end{array}$ \\
\hline & & 2 & $420(91.3 \%)$ & 2 & $420(91.3 \%)$ \\
\hline \multirow[t]{3}{*}{ Second premolar } & \multirow[t]{3}{*}{423} & 1 & $112(26.5 \%)$ & $\begin{array}{l}1 \\
2\end{array}$ & $\begin{array}{c}75(17.7 \%) \\
37(8.8 \%)\end{array}$ \\
\hline & & 2 & $311(73.5 \%)$ & 2 & $311(73.5 \%)$ \\
\hline & & & & 3 & $163(39.7 \%)$ \\
\hline \multirow[t]{3}{*}{ First molar } & \multirow[t]{3}{*}{410} & 3 & $410(100 \%)$ & 4 & $245(59.8 \%)$ \\
\hline & & & & 5 & $2(0.5 \%)$ \\
\hline & & & & 3 & $210(48.3 \%)$ \\
\hline \multirow[t]{4}{*}{ Second molar } & \multirow[t]{4}{*}{435} & 3 & $435(100 \%)$ & 4 & $224(51.5 \%)$ \\
\hline & & & & 5 & $1(0.2 \%)$ \\
\hline & & & & 1 & $33(13.8 \%)$ \\
\hline & & 1 & $114(47.9 \%)$ & 2 & $28(11.8 \%)$ \\
\hline \multirow[t]{3}{*}{ Third molar } & \multirow[t]{3}{*}{238} & & & 3 & $53(22.3 \%)$ \\
\hline & & 3 & $124(52.1 \%)$ & 3 & $119(50 \%)$ \\
\hline & & 3 & $124(52.1 \%)$ & 4 & $5(2.1 \%)$ \\
\hline
\end{tabular}

TABLE 2: Anatomy of roots and root canals in mandibular teeth.

\begin{tabular}{|c|c|c|c|c|c|}
\hline Tooth & Number of studied teeth & Roots & $N(\%)$ & Canals & $N(\%)$ \\
\hline Central incisor & 512 & 1 & $512(100 \%)$ & $\begin{array}{l}1 \\
2\end{array}$ & $\begin{array}{c}509(99.4 \%) \\
3(0.6 \%)\end{array}$ \\
\hline Lateral incisor & 500 & 1 & $500(100 \%)$ & $\begin{array}{l}1 \\
2\end{array}$ & $\begin{array}{c}496(99.2 \%) \\
4(0.8 \%)\end{array}$ \\
\hline Canine & 521 & 1 & $521(100 \%)$ & 1 & $\begin{array}{c}520(99.8 \%) \\
1(0.2 \%)\end{array}$ \\
\hline First premolar & 490 & 1 & $490(100 \%)$ & $\begin{array}{l}1 \\
2\end{array}$ & $\begin{array}{c}437(89.2 \%) \\
53(10.8 \%)\end{array}$ \\
\hline Second premolar & 443 & 1 & $\begin{array}{c}442(99.8 \%) \\
1(0.2 \%)\end{array}$ & $\begin{array}{l}1 \\
2 \\
2\end{array}$ & $\begin{array}{c}399(90.1 \%) \\
43(9.7 \%) \\
1(0.2 \%)\end{array}$ \\
\hline First molar & 407 & 2 & $407(100 \%)$ & $\begin{array}{l}2 \\
3 \\
4\end{array}$ & $\begin{array}{c}2(0.5 \%) \\
320(78.6 \%) \\
85(20.9 \%)\end{array}$ \\
\hline Second molar & 398 & 1 & $396(99.5 \%)$ & $\begin{array}{l}2 \\
2 \\
3 \\
4\end{array}$ & $\begin{aligned} 2 & (0.5 \%) \\
47 & (11.8 \%) \\
327 & (82.2 \%) \\
22 & (5.5 \%)\end{aligned}$ \\
\hline Third molar & 210 & 1 & $42(20 \%)$ & $\begin{array}{l}1 \\
2 \\
2 \\
3\end{array}$ & $\begin{array}{c}1(0.5 \%) \\
41(19.5 \%) \\
45(21.4 \%) \\
123(58.6 \%)\end{array}$ \\
\hline
\end{tabular}

canals in MB. Ghoncheh et al. (Iran) [28], Silva et al. (Brazil) [31], Ceperuelo et al. (Spain) [33], Betancourt et al. (Chili) [37], Al-Fouzan et al. (Saudi Arabia) [38], and Li et al. (China) [39] reported 14\%, 32\%, 75\%, 48\%, 19.7\%, and $41.3 \%$, respectively, of the prevalence of MB2 in maxillary second molar.

The maxillary third molar in our study was defined as single-rooted in $47.9 \%$ and three-rooted in $52.1 \%$, and the system of root canals could consist of one, two, three, or more canals as shown in (Table 1). Similar results were found in a study of Sidow et al. (USA) [40], in which, it was found
$15 \%$ of third molars had one root and $45 \%$ had three roots, and the number of canals ranged from 1 to 6 in teeth with one root and 2 to 5 in teeth with 3 roots. A study by Tomaszewska et al. (Poland) [41] reported the one-rooted maxillary third molar in $38.5 \%$ of cases and $61.5 \%$ were three-rooted. The prevalence of one, three, and four canals were $23.1 \%, 46.1 \%$, and $15.4 \%$, respectively. Singh and Pawar (India) [42] found three-canal system of maxillary third molar in $43 \%$ of cases and four-canal system in 5\%.

In this study, for mandibular teeth, it was identified in central and lateral incisors and canines, one canal in $99.4 \%$, 
$99.2 \%$, and $99.8 \%$, respectively, and two canals in $0.6 \%, 0.8 \%$, and $0.2 \%$ of cases, respectively. These findings are consistent with other studies, where one canal was recorded in central incisors in 99.7\% in Madeira and Hetem (Brazil) [43] and 99\% in Walker (China) [44]. For lateral incisors, studies have reported the presence of 2 canals in $1.3 \%$ (Mexico) [11], $0.8 \%$ (Brazil) [43], and 1\% (China) [44]. The presence of 2 canals in canines was $20.48 \%$ and $20.4 \%$ in studies by Rahimi et al. (Iran) [45] and Amardeep et al. (India) [16].

The mandibular first premolar was found as singlerooted in $100 \%$ of cases. One canal was found in $89.2 \%$, and two canals in $10.8 \%$ of cases. This coincides with the results of Bulut (Turkey) [17], in which 1 canal was recorded in 94.2\%, Llena et al. (Spain) [46], Alhadainy (Egypt) [47], and Sobhani et al. (Iran) [48], and one canal was found in $78.1 \%, 61.2 \%$, and $90.8 \%$, respectively. The presence of 2 canals was recorded by Zillich and Dowson (USA) [49] in 18.9\%, Abraham and Gopinath (Emirate) [50] $35 \%$, Dou et al. (china) [51] with 34.27\%, Bürklein et al. (Germany) [22] with $21.9 \%$, and Singh and Pawar (India) [52] with $22 \%$.

The mandibular second premolar had one root in $99.8 \%$, and it had two roots in one clinical case $(0.2 \%)$. When analyzing the root canal system, two canals were defined in 9.7\% of cases. Similar data were found in studies by Bulut et al. (Turkey) [17] and Llena et al. (Spain) [46] with $98.9 \%$ and $90.6 \%$, respectively, for the prevalence of one canal. Al-Qudah and Awawdeh (Jordan) [53], Bürklein et al. (Germany) [22], Bolhari et al. (Iran) [54], and Singh and Pawar (India) [52] recorded the prevalence of 2 canals in $22.8 \%, 3.6 \%, 8.7 \%$, and $42 \%$ of cases, respectively.

The mandibular first molar had two roots in $100 \%$ of the cases. And, the anatomy of the root canal system could be two-canal, three-canal, and four-canal. Most often, there are three canals in $78.6 \%$ of observations. Similar data were found in Vertucci (USA) 59\% [10], Pineda and Kuttler (Mexico) 57\% [11], Celikten (Turkey) 84.6\% [55], of cases of three-canal first molars. Skidmore and Bjorndal (USA) [56] have revealed $55.5 \%$ of cases. Zhang et al. (China) [57] recorded 56\% and Caputo et al. (Brazil) [58] recorded 75.1\% of cases of three-canals in mandibular first molars. The fourcanal system of the first molar was defined in our study in $20.9 \%$ of cases; it was also described in the literature by Wasti et al. (Pakistan) [26] in $43.3 \%$ of cases, Caputo et al. (Brazil) [58] in 23.7\%, Hung et al. (Taiwan) [59] in 40.5\%, Celikten et al. (Turkey) [55] in 10.4\%, Al-Qudah and Awawdeh (Jordan) [60] in 45.8\%, and Pattanshetti et al. (Kuwait) [61] in $46.4 \%$.

When analyzing the structure of the root canal system of the mandibular second molar, it was defined to be a two-, three-, and four-canal systems. $82.2 \%$ of cases had three canals. The most similar data were found in Celikten et al. (Turkey) [55], where $85.9 \%$ of three canals were recorded, and Neelakantan et al. (India) [62], in which most of second molars had two roots with three canals in $87.8 \%$. Zhang et al. (China) [57] and Pawar et al. (India) [63] defined 3-canal system in $46 \%$ and $35.5 \%$ of cases.

The mandibular third molar was revealed as two-rooted in most cases (80\%), and the canal system could have twoand three-canals, and these results agreed with other studies of the anatomy of third molar, as in Kuzekanani et al. (Iran) [64] where $73 \%$ of cases had 2 roots, and a study by Sidow et al. (USA) [40], where $77 \%$ of two roots were defined.

\section{Conclusions}

The root canal system varies greatly among populations and regions and even in different individuals within the same population, and using CBCT scanning is an effective technique in investigating the root canal system.

\section{Abbreviations}

CBCT: Cone-beam computed tomography

3D: Three-dimensional

MB: Mesiobuccal root

DB: Distobuccal root.

\section{Data Availability}

The data used to support the findings of this study are included within the article.

\section{Conflicts of Interest}

The authors declare that they have no conflicts of interest.

\section{Acknowledgments}

The publication has been prepared with the support of the "RUDN University Program 5-100."

\section{References}

[1] S. Rahimi and N. Ghasemi, "Maxillary first molar with two root canals," Sultan Qaboos University Medical Journal, vol. 13, no. 2, pp. 346-349, 2013.

[2] V. S. Blinov, M. V. Kartashov, S. E. Zholudev, and O. S. Zornikova, "Estimation of the cone-beam computed tomography in diagnostics of the molar root system anatomy of the mandible and maxilla," Radiology-Practice, vol. 59, no. 5, pp. 6-15, 2016.

[3] S. Patel, C. Durack, F. Abella, H. Shemesh, M. Roig, and K. Lemberg, "Cone beam computed tomography in Endodontics-a review," International Endodontic Journal, vol. 48, no. 1, pp. 3-15, 2015.

[4] V. V. Aliamovskii, O. A. Levenets, and A. A. Levenets, "Multiple anatomical variations of structure molars maxilla," Endodontology Today, no. 4, pp. 22-25, 2014.

[5] Y. A. Makedonova, I. V. Firsova, S. V. Poroyskyi, N. N. Trigolos, and E. B. Marymova, "Clinical-Radiological features of the structure of the tooth cavity and root canals of the upper," Contemporary Problems of Science and Education, no. 1, p. 1308, 2015.

[6] T. C. Blattner, N. George, C. C. Lee, V. Kumar, and C. D. Yelton, "Efficacy of cone-beam computed tomography as a modality to accurately identify the presence of second mesiobuccal canals in maxillary first and second molars: a pilot study," Journal of Endodontics, vol. 36, no. 5, pp. 867-870, 2010.

[7] J. Martos, C. Lubian, L. F. Silveria, L. A. Suita de Castro, and C. M. Ferrer Luque, "Morphologic analysis of the root apex in 
human teeth," Journal of Endodontics, vol. 36, no. 4, pp. 664-667, 2010.

[8] Y. Kim, S. J. Lee, and J. Woo, "Morphology of maxillary first and second molars analyzed by cone-beam computed tomography in a Korean population: variations in the number of roots and canals and the incidence of fusion," Journal of Endodontics, vol. 38, no. 8, pp. 1063-1068, 2012.

[9] M. Iqbal and E. Fillmore, "Preoperative predictors of number of root canals clinically detected in maxillary molars: a pennendo database study," Journal of Endodontics, vol. 34, no. 4, pp. 413-416, 2008.

[10] F. J. Vertucci, "Root canal anatomy of the human permanent teeth," Oral Surgery, Oral Medicine, Oral Pathology, vol. 58, no. 5, pp. 589-599, 1984.

[11] F. Pineda and Y. Kuttler, "Mesiodistal and buccolingual roentgenographic investigation of 7,275 root canals," Oral Surgery, Oral Medicine, Oral Pathology, vol. 33, no. 1, pp. 101-110, 1972.

[12] F. S. Weine, H. J. Healey, H. Gerstein, and L. Evanson, "Canal configuration in the mesiobuccal root of the maxillary first molar and its endodontic significance," Oral Surgery, Oral Medicine, Oral Pathology, vol. 28, no. 3, pp. 419-425, 1969.

[13] M. K. Calişkan, Y. Pehlivan, F. Sepetcioğlu, M. Türkün, and S. Ş. Tuncer, "Root canal morphology of human permanent teeth in a Turkish population," Journal of Endodontics, vol. 21, no. 4, pp. 200-204, 1995.

[14] P. Jain, S. Balasubramanian, J. Sundaramurthy, and V. Natanasabapathy, "A cone beam computed tomography of the root canal morphology of maxillary anterior teeth in an institutional-based study in Chennai urban population: an in vitro study," Journal of International Society of Preventive and Community Dentistry, vol. 7, no. 8, pp. 68-74, 2017.

[15] S. Sert and G. S. Bayirli, "Evaluation of the root canal configurations of the mandibular and maxillary permanent teeth by gender in the Turkish population," Journal of Endodontics, vol. 30, no. 6, pp. 391-398, 2004.

[16] N. S. Amardeep, S. Raghu, and V. Natanasabapathy, "Root canal morphology of permanent maxillary and mandibular canines in Indian population using cone beam computed tomography," Anatomy Research International, vol. 2014, Article ID 731859, 7 pages, 2014.

[17] D. G. Bulut, E. Kose, G. Ozcan, A. E. Sekerci, E. M. Canger, and Y. Sisman, "Evaluation of root morphology and root canal configuration of premolars in the Turkish individuals using cone beam computed tomograpy," European Journal of Dentistry, vol. 9, no. 4, pp. 551-557, 2015.

[18] J. D. Pecora, P. C. Saquy, M. D. Sousa Neto, and J. B. Woelfel, "Root form and root canal anatomy of maxillary first premolars," Brazilian Dental Journal, vol. 2, no. 2, pp. 87-94, 1992.

[19] K. Kerekes and L. Tronstad, "Morphometric observations on root canals of human premolars," Journal of Endodontics, vol. 3, no. 2, pp. 74-79, 1977.

[20] D. Green, "Double canals in single roots," Oral Surgery, Oral Medicine, Oral Pathology, vol. 35, no. 5, pp. 689-696, 1973.

[21] E. Ok, M. Altunsoy, B. G. Nur, O. S. Aglarci, M. Çolak, and E. Güngör, "A cone-beam computed tomography study of root canal morphology of maxillary and mandibular premolars in a Turkish population," Acta Odontologica Scandinavica, vol. 72, no. 8, pp. 701-706, 2014.

[22] S. Bürklein, R. Heck, and E. Schäfer, "Evaluation of the root canal anatomy of maxillary and mandibular premolars in a selected German population using cone-beam computed tomographic data," Journal of Endodontics, vol. 43, no. 9, pp. 1448-1452, 2017.

[23] L. A. Awawdeh, H. Abdullah, and A. A. Al-Qudah, "Root form and canal morphology of Jordanian maxillary first premolars," Journal of Endodontics, vol. 34, no. 8, pp. 956-961, 2008.

[24] M. Elnour, A. Khabeer, and E. AlShwaimi, "Evaluation of root canal morphology of maxillary second premolars in a Saudi Arabian sub-population: an in vitro microcomputed tomography study," Saudi Dental Journal, vol. 28, no. 4, pp. 162-168, 2016.

[25] H. Pomeranz and G. Fishelberg, "The secondary mesiobuccal canal of maxillary molars," Journal of the American Dental Association, vol. 88, no. 1, pp. 119-124, 1974.

[26] F. Wasti, A. C. Shearer, and N. H. F. Wilson, "Root canal systems of the mandibular and maxillary first permanent molar teeth of south Asian Pakistanis," International Endodontic Journal, vol. 34, no. 4, pp. 263-266, 2001.

[27] N. Imura, G. I. Hata, and T. Toda, "Two canals in mesiobuccal roots of maxillary molars," International Endodontic Journal, vol. 31, no. 6, pp. 410-414, 1998.

[28] Z. Ghoncheh, B. M. Zade, and M. J. Kharazifard, "Root morphology of the maxillary first and second molars in an Iranian population using cone beam computed tomography," Journal of Dentistry, vol. 14, no. 3, pp. 115-122, 2017.

[29] J. N. R. Martins, D. Marques, A. Mata, and J. Caramês, "Root and root canal morphology of the permanent dentition in a Caucasian population: a cone-beam computed tomography study," International Endodontic Journal, vol. 50, no. 11, pp. 1013-1026, 2017.

[30] R. Ratanajirasut, A. Panichuttra, and S. Panmekiate, "A Conebeam computed tomographic study of root and canal morphology of maxillary first and second permanent molars in a Thai population," Journal of Endodontics, vol. 44, no. 1, pp. 56-61, 2018.

[31] E. J. Silva, Y. Nejaim, A. I. Silva, F. Haiter-Neto, A. A. Zaia, and N. Cohenca, "Evaluation of root canal configuration of maxillary molars in a Brazilian population using cone-beam computed tomographic imaging: an in vivo study," Journal of Endodontics, vol. 40, no. 2, pp. 173-176, 2014.

[32] J. Guo, A. Vahidnia, P. Sedghizadeh, and R. Enciso, "Evaluation of root and canal morphology of maxillary permanent first molars in a north American population by cone-beam computed tomography," Journal of Endodontics, vol. 40, no. 5, pp. 635-639, 2014.

[33] D. Ceperuelo, M. Lozano, F. D. Sindreu, and M. Mercadé, "Root canal morphology of Chalcolithic and early bronze age human populations of El MiradorCave (Sierra de Atapuerca, Spain)," Anatomical Record, vol. 297, no. 12, pp. 2342-2348, 2014.

[34] R. M. A. Shalabi, O. E. Omer, J. Glennon, M. Jennings, and N. M. Claffey, "Root canal anatomy of maxillary first and second permanent molars," International Endodontic Journal, vol. 33, no. 5, pp. 405-414, 2000.

[35] J. C. Kulild and D. D. Peters, "Incidence and configuration of canal systems in the mesiobuccal root of maxillary first and second molars," Journal of Endodontics, vol. 16, no. 7, pp. 311-317, 1990.

[36] A. M. Alavi, A. Opasanon, Y. L. Ng, and K. Gulabivala, "Root and canal morphology of Thai maxillary molars," International Endodontic Journal, vol. 35, no. 5, pp. 478-485, 2002.

[37] P. Betancourt, P. Navarro, M. Cantin, and R. Fuentes, “Conebeam computed tomography study of prevalence and location 
of MB2canal in the mesiobuccal root of the maxillary second molar," International Journal of Clinical and Experimental Medicine, vol. 8, no. 6, pp. 9128-9134, 2015.

[38] K. S. Al-Fouzan, H. F. Ounis, K. Merdad, and K. Al-Hezaimi, "Incidence of canal systems in the mesio-buccal roots of maxillary first and second molarsin Saudi Arabian population," Australian Endodontic Journal, vol. 39, no. 3, pp. 98-101, 2013.

[39] L. Li, F. L. Zhan, and Y. W. Jin, "Preliminary study on root canal morphology of maxillary second molars," Shanghai Kou Qiang Yi Xue, vol. 23, no. 2, pp. 179-183, 2014.

[40] S. J. Sidow, L. A. West, F. R. Liewehr, and R. J. Loushine, "Root canal morphology of human maxillary and mandibular third molars," Journal of Endodontics, vol. 26, no. 11, pp. 675-678, 2000.

[41] I. M. Tomaszewska, B. Leszczyński, A. Wróbel, T. Gładysz, and H. F. Duncan, "A micro-computed tomographic (microCT) analysis of the root canal morphology of maxillary third molar teeth," Annals of Anatomy-Anatomischer Anzeiger, vol. 215, pp. 83-92, 2018.

[42] S. Singh and M. Pawar, "Root canal morphology of south Asian Indian maxillary molar teeth," European Journal of Dentistry, vol. 9, no. 1, pp. 133-144, 2015.

[43] M. C. Madeira and S. Hetem, "Incidence of bifurcations in mandibular incisors," Oral Surgery, Oral Medicine, Oral Pathology, vol. 36, no. 4, pp. 589-591, 1973.

[44] R. T. Walker, "The root canal anatomy of mandibular incisors in a southern Chinese population," International Endodontic Journal, vol. 21, no. 3, pp. 218-223, 1988.

[45] S. Rahimi, A. S. Milani, S. Shahi, Y. Sergiz, S. Nezafati, and M. Lotfi, "Prevalence of two root canals in human mandibular anterior teeth in an Iranian population," Indian Journal of Dental Research, vol. 24, no. 2, pp. 234-236, 2013.

[46] C. Llena, J. Fernandez, P. S. Ortolani, and L. Forner, "Conebeam computed tomography analysis of root and canal morphology of mandibular premolars in a Spanish population," Imaging Science in Dentistry, vol. 44, no. 3, pp. 221-227, 2014.

[47] H. A. Alhadainy, "Canal configuration of mandibular first premolars in an Egyptian population," Journal of Advanced Research, vol. 4, no. 2, pp. 123-128, 2013.

[48] M. A. Sobhani, H. Razmi, and M. Sadegh, "Evaluation of anatomy and morphology of human mandibular premolar teeth by cone-beam computed tomography in Iranian population," Journal of Dental Medicine, vol. 26, no. 3, 2013.

[49] R. Zillich and J. Dowson, "Root canal morphology of mandibular first and second premolars," Oral Surgery, Oral Medicine, Oral Pathology, vol. 36, no. 5, pp. 738-744, 1973.

[50] S. B. Abraham and V. K. Gopinath, "Root canal anatomy of mandibular first premolars in an Emirati subpopulation: a laboratory study," European Journal of Dentistry, vol. 9, no. 4, pp. 476-482, 2015.

[51] L. Dou, D. Li, T. Xu, Y. Tang, and D. Yang, "Root anatomy and canal morphology of mandibular first premolars in a Chinese population," Scientific Reports, vol. 7, no. 1, p. 750, 2017.

[52] S. Singh and M. Pawar, "Root canal morphology of south Asian Indian mandibular premolar teeth," Journal of Endodontics, vol. 40, no. 9, pp. 1338-1341, 2014.

[53] A. A. Al-Qudah and L. A. Awawdeh, "Root form and canal morphology of mandibular premolars in a Jordanian population," International Endodontic Journal, vol. 41, no. 3, pp. 240-248, 2008.

[54] B. Bolhari, H. Assadian, and T. Fattah, "Evaluation of the root canal morphology of mandibular second premolars in an
Iranian population," Journal of Dentistry, vol. 10, no. 6, pp. 516-521, 2013.

[55] B. Celikten, P. Tufenkci, U. Aksoy et al., "Cone beam CT evaluation of mandibular molar root canal morphology in a Turkish Cypriot population," Clinical Oral Investigations, vol. 20, no. 8, pp. 2221-2226, 2016.

[56] A. E. Skidmore and A. M. Bjorndal, "Root canal morphology of the human mandibular first molar," Oral Surgery, Oral Medicine, Oral Pathology, vol. 32, no. 5, pp. 778-784, 1971.

[57] R. Zhang, H. Wang, Y. Y. Tian, X. Yu, T. Hu, and P. M. Dummer, "Use of cone-beam computed tomography to evaluate root and canal morphology of mandibular molars in Chinese individuals," International Endodontic Journal, vol. 44, no. 11, pp. 990-999, 2011.

[58] B. V. Caputo, G. A. Noro Filho, D. M. de Andrade Salgado, C. Moura-Netto, E. M. Giovani, and C. Costa, "Evaluation of the root canal morphology of molars by using cone-beam computed tomography in a Brazilian population: part I," Journal of Endodontics, vol. 42, no. 11, pp. 1604-1607, 2016.

[59] C. C. Huang, Y. C. Chang, M. C. Chuang et al., "Evaluation of root and canal systems of mandibular first molars in Taiwanese individuals using cone-beam computed tomography," Journal of the Formosan Medical Association, vol. 109, no. 4, pp. 303-308, 2010.

[60] A. A. Al-Qudah and L. A. Awawdeh, "Root and canal morphology of mandibular first and second molar teeth in a Jordanian population," International Endodontic Journal, vol. 42, pp. 775-784, 2009.

[61] N. Pattanshetti, M. Gaidhane, and A. M. Al Kandari, "Root and canal morphology of the mesiobuccal and distal roots of permanent first molars in a Kuwait population: a clinical study," International Endodontic Journal, vol. 41, no. 9, pp. 755-762, 2008.

[62] P. Neelakantan, C. Subbarao, C. V. Subbarao, and M. Ravindranath, "Root and canal morphology of mandibular second molars in an Indian population," Journal of Endodontics, vol. 36, no. 8, pp. 1319-1322, 2010.

[63] A. M. Pawar, M. Pawar, A. Kfir et al., "Root canal morphology and variations in mandibular second molar teeth of an Indian population: an in vivo cone-beam computed tomography analysis," Clinical Oral Investigations, vol. 21, no. 9, pp. 2801-2809, 2017.

[64] M. Kuzekanani, J. Haghani, and H. Nosrati, "Root and canal morphology of mandibular third molars in an Iranian population," Journal of Dental Research, Dental Clinics, Dental Prospects, vol. 6, no. 3, pp. 85-88, 2012. 


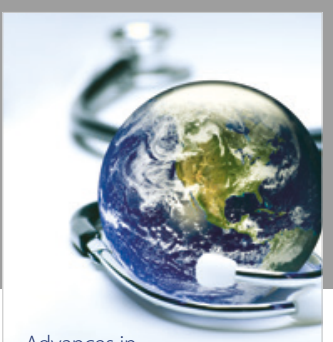

Advances in
Public Health

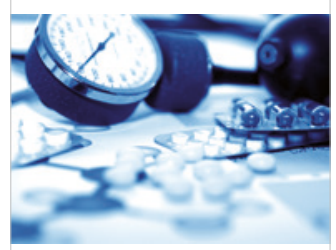

Case Reports in

Medicine

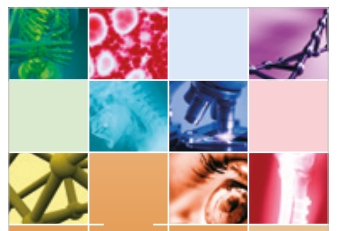

niernational Journal of

Biomaterials
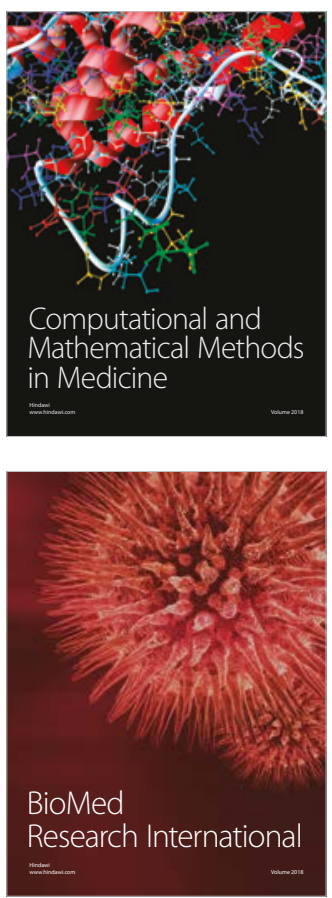

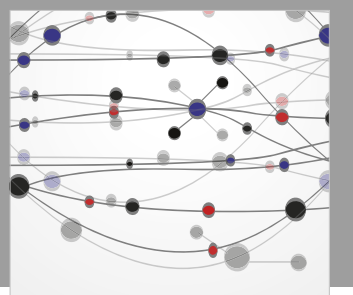

The Scientific World Journal Dentistry

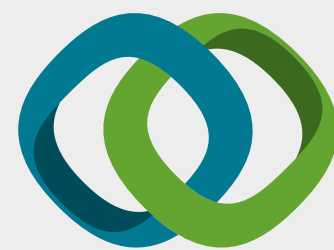

Hindawi

Submit your manuscripts at

www.hindawi.com
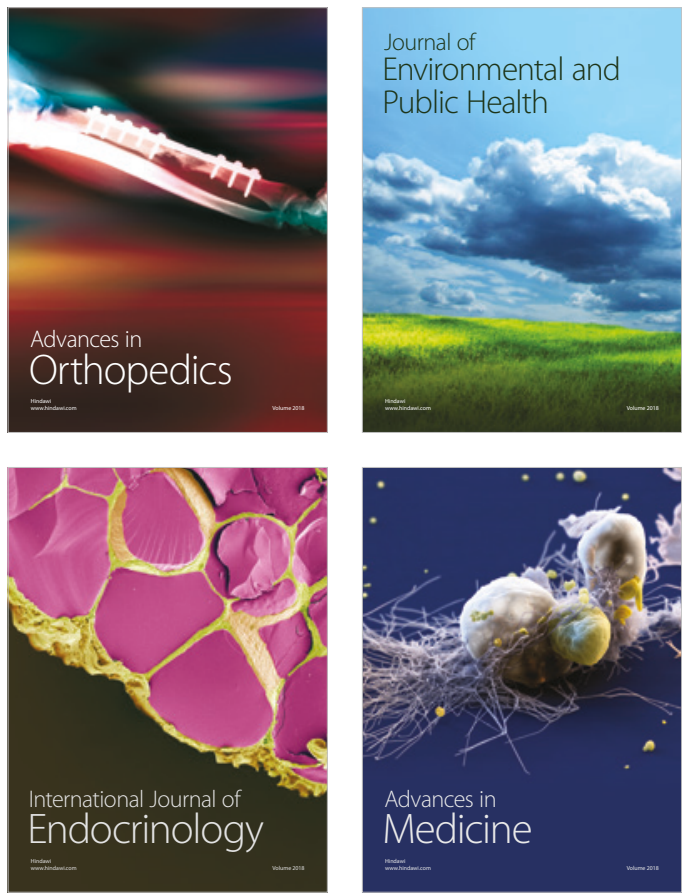
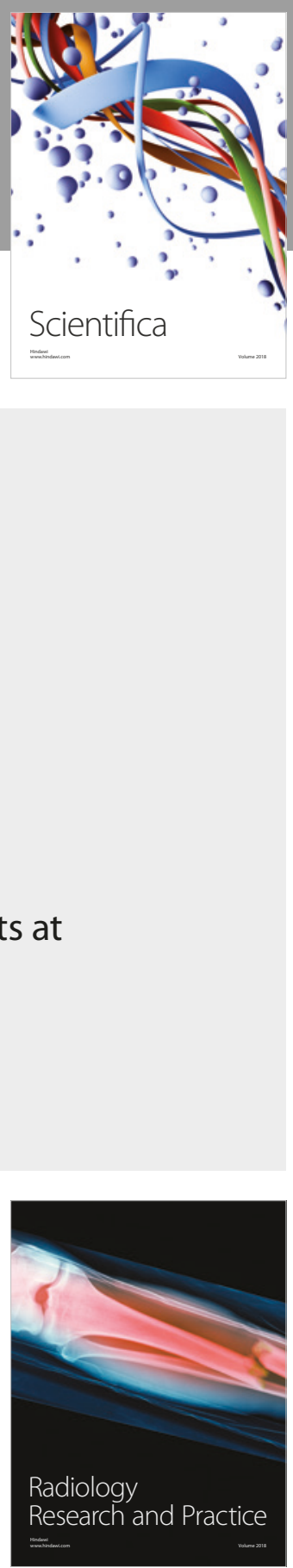

Scientifica

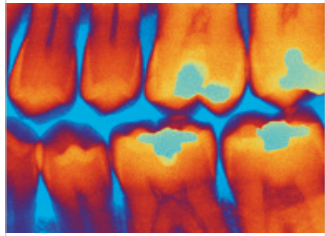

Case Reports in

Dentistry
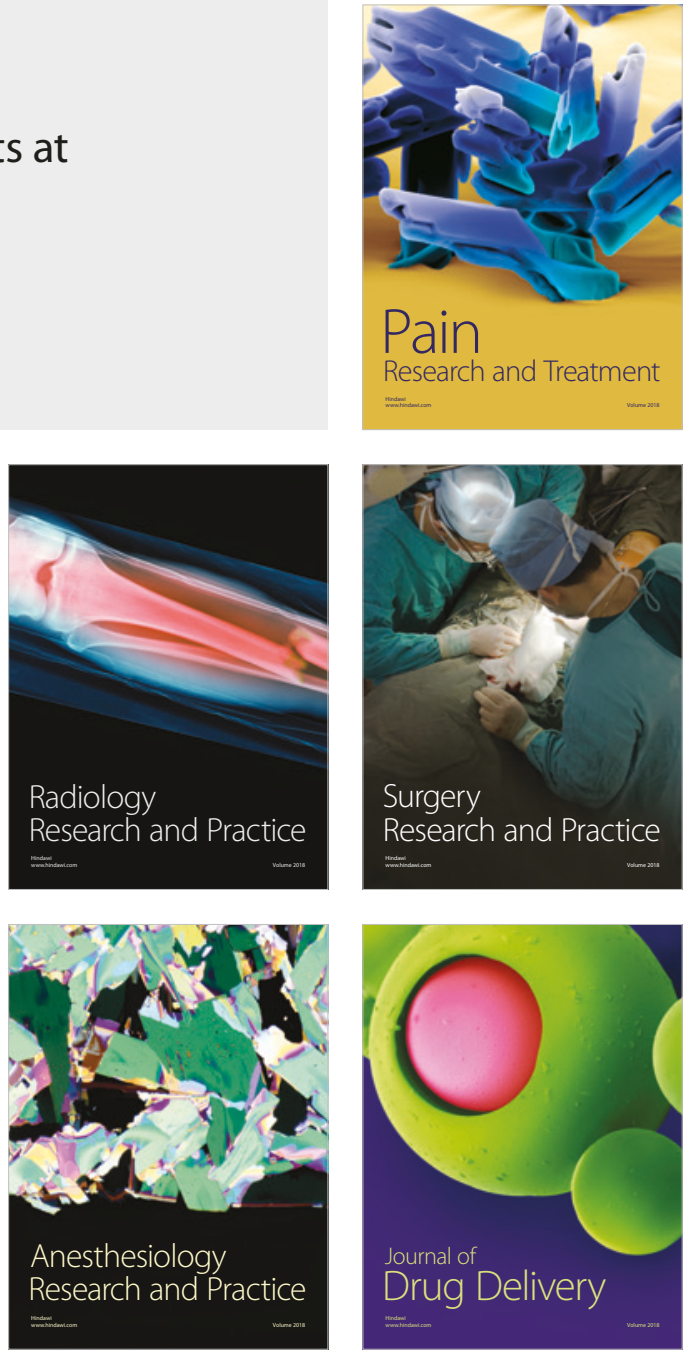